\title{
Palliative Care in Movement Disorders: an Evolving Field
}

\author{
Zachary A. Macchi ${ }^{1}$ (1) $\cdot$ Christopher G. Tarolli ${ }^{2,3} \cdot$ Benzi M. Kluger ${ }^{2,3,4}$ \\ Accepted: 13 January 2021 / Published online: 28 January 2021 \\ (C) The Author(s), under exclusive licence to Springer Science+Business Media, LLC part of Springer Nature 2021
}

\begin{abstract}
Purpose of Review This review summarizes the current state of evidence for palliative care (PC) in movement disorders, describes the application of PC to clinical practice, and suggests future research directions.

Recent Findings PC needs are common in persons living with movement disorders and their families from the time of diagnosis through end-of-life and contribute to quality of life. Early advance care planning is preferred by patients, impacts outcomes and is promoted by PC frameworks. Systematic assessment of non-motor symptoms, psychosocial needs and spiritual/existential distress may address gaps in current models of care. Several complementary and emerging models of PC may be utilized to meet the needs of this population.

Summary A PC approach may identify and improve important patient and caregiver-centered outcomes. As a relatively new application of PC, there is a need for research to adapt, develop and implement approaches to meet the unique needs of this population.
\end{abstract}

Keywords Advance care planning(MeSH ID: D032722) · End of life care (MeSHID: D013727) · Movement disorders (MeSH ID: D009069) · Palliative care (MeSH ID: D010166) · Quality of life (MeSH ID: D011788)

\section{Introduction}

Movement disorders encompass a diverse set of illnesses characterized by excessive movement (tremor, dystonia, chorea), deficient movement (parkinsonism), or problems with movement control (ataxia). While the genetic and neurodegenerative diseases associated with movement disorders vary in many clinical aspects they are uniformly associated with

Zachary A. Macchi and Christopher G. Tarolli contributed equally to this work.

This Article is part of the Topical Collection on Movement Disorders

Zachary A. Macchi

Zachary.macchi@cuanschutz.edu

1 Department of Neurology, University of Colorado, Aurora, CO Building 400, Mail Stop F429, 12469 E 17th Place, Aurora, CO 80045, USA

2 Department of Neurology, University of Rochester, Rochester, NY, USA

3 Center for Health + Technology, University of Rochester, Rochester, NY, USA

4 Department of Medicine, Palliative Care Division, University of Rochester, Rochester, NY, USA non-motor symptoms, disability, diminished quality of life, and increased mortality $[1,2]$. Palliative care (PC) is an approach to the care of persons living with serious illness focused on improving quality of life (QOL) by addressing medical symptoms, psychosocial issues, spiritual wellbeing and advance care planning [3]. While traditionally associated with cancer and end-of-life care (hospice), PC is now recognized to be appropriate earlier in the course of illness, alongside curative and restorative therapies, and may be applied in diverse settings (inpatient, outpatient, community) by both PC specialists and non-specialists including neurologists [4]. Given the needs of persons living with movement disorders, it is not surprising that they were one of the first targets of the emerging field of Neuropalliative care [5].

\section{Neuropalliative Care}

Neuropalliative care is the application of PC to neurologic illness and acknowledges that they present unique challenges to the physical, emotional, social and spiritual wellbeing of affected individuals [6,7]. Awareness of this field is growing and in recent years neuropalliative care has attracted increased recognition from both the medical community and mainstream media $[2,8,9]$. Although a need for work in this field 
was recognized over two decades ago [10], progress in this field had been slow until recently. During the 2017 American Academy of Neurology annual conference the first annual Neuropalliative Care Summit was held to connect persons with interest in this field and set priorities for clinical practice, research, and education [11“]. We highlight some notable advances in our understanding of PC's role in movement disorders, describe areas for application in clinical practice, and suggest future research directions.

\section{Palliative Care Needs in Movement Disorders}

PC needs are common among many of the degenerative and inherited movement disorders, extending from diagnosis throughout the illness $[12,13]$. Needs stem from the high disease burden with physical, psychological, social, financial, and spiritual burden described across a wide spectrum of movement disorders [6]. Additionally, palliative needs change over the course of movement disorders with periods of stability and relatively low burden punctuated by periods of high needs (Fig. 1). Because of the heterogeneity of progression, periods of increased burden may be unexpected, and this uncertainty may itself compound other sources of distress.

\section{Symptom Burden}

Symptom burden is high and can have a substantial impact on QOL among those with movement disorders [14-16]. In midto late-stage Parkinson's disease (PD), for example, patients have comparable symptom burden to individuals with advanced cancer $[7,17]$. Those with an atypical parkinsonian syndrome have similar symptomatic needs, though may have higher burden on average and more rapid progression $\left[15^{*}\right]$. Similarly, individuals with HD have profound symptomatic needs throughout the disease course [18]. While the defining characteristic of these conditions is abnormal movement, nonmotor symptoms like pain and neuropsychiatric symptoms are common and significant drivers of QOL, an effect that may be heightened as they are frequently under-recognized and under-treated [19]. The prevalence of depression in PD is estimated around $40 \%$, yet is only recognized in around half of patients $[19,20]$. Rates of neuropsychiatric symptoms are similar among those with HD with mood disorders, irritability, and anxiety common throughout the disease course [21]. Apathy and agnosia may also be seen, are frequently challenging to treat, and may cause under-reporting of symptoms by patients and family members $[22,23]$. While not traditionally associated with movement disorders, pain is now recognized as a common and burdensome symptom among those with PD and other parkinsonian syndromes with dystonic, musculoskeletal, neuropathic, and central pain described [24]. There can be substantial interplay between non-motor symptoms (e.g. pain can affect sleep and mood) which may further impact overall QOL [7, 20].

\section{Other Domains of Palliative Care Needs}

Most degenerative and inherited movement disorders are associated with progressive disability and loss of independence. Beyond the direct burden on QOL, disability can lead to isolation, changes in social roles, and threats to personhood. Cicely Saunders coined the term "total pain" to describe these

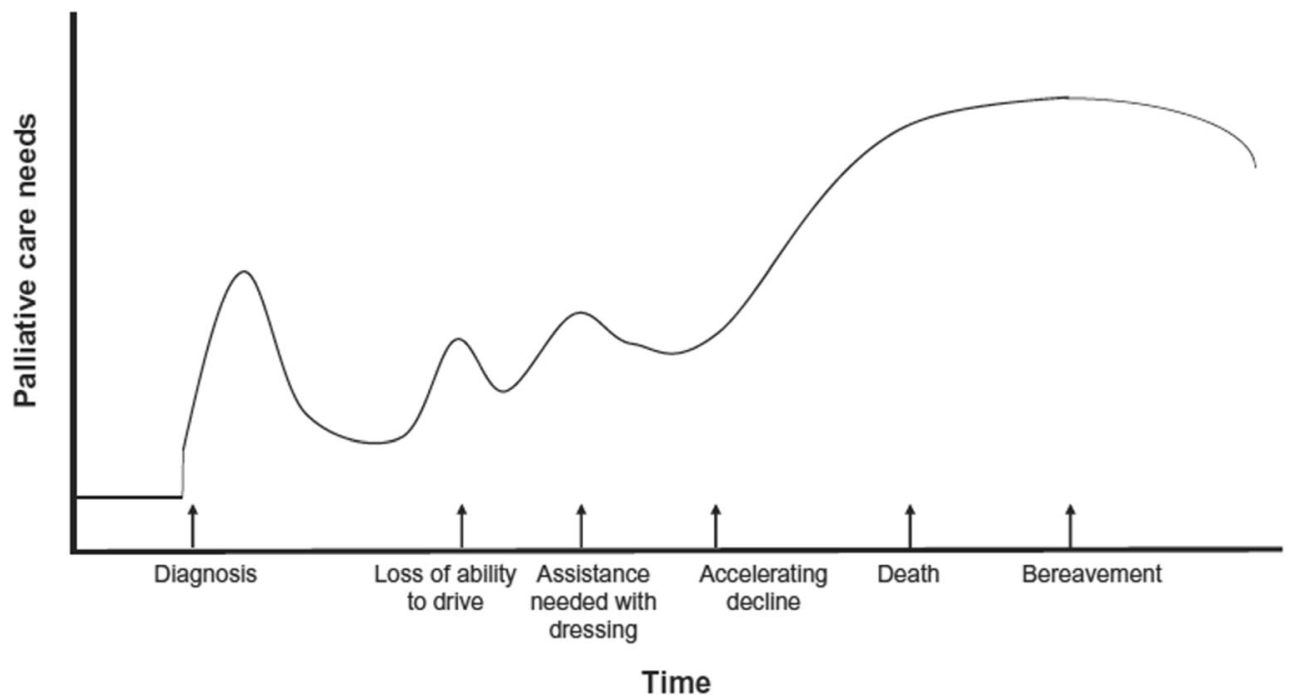

FIG. 1 Plot demonstrating the change in an individual's palliative care needs throughout the natural progression of neurodegenerative disease. Individual needs fluctuate over time with increases reflective of major events such as early psychologic stress surrounding diagnosis, medication titration for symptom management, access to resources and caregiver support, and worsening disease severity. The end-of-life phase is characterized by a requirement for maximal palliative care needs that transfers to caregiver and families following death and during bereavement. Adopted from "Glover TL, Kluger BM, Handbook of Clinical Neurology, Vol 167 (3 ${ }^{\text {rd }}$ series) Geriatric Neurology. 2019.” [98] 
broader "physical, emotional, social, and spiritual dimensions of distress," which are common among those with movement disorders [13, 25-27]. Emotional pain goes beyond psychiatric disorders such as depression to include other difficult emotions that are a normal reaction to serious illness. Grief, meaning a sense of current and future losses, is distinct from depression and common among patients and family members [28]. A 2018 study assessing the palliative needs of those with PD identified grief as a common feature with a significant impact on QOL $\left[7^{\circ}\right]$. Grief may even pre-date symptom onset in those with a family history of HD who undergo presymptomatic genetic testing [29]. Social pain may arise in persons living with movement disorders including loss of employment [30], changes in social roles [31], and loss of social connections [26]. Spiritual and existential pain may be conceptualized in terms of loss of hope (demoralization), meaning, and faith [32]. Not surprisingly, PD and other incurable neurodegenerative illnesses may adversely impact spiritual wellbeing in multiple ways [33], and demoralization is quite common [34].

The impact of neurodegenerative movement disorders extends beyond the patient. Care partners and families must cope with the substantial burden of movement disorders on their loved one. They often face a dramatic change in family dynamics with expectations to provide complex supportive care as the diseases progress. Care partner burnout is highly correlated with patient disability and symptom burden, and care partner social, emotional, and spiritual needs are similar to the needs of patients [35-37]. Depression and poor QOL are also well-described among care partners of individuals with life-limiting medical conditions, with potentially greater burden among care partners of those with neurodegenerative diseases [38].

\section{Advance Care Planning \& Goals of Care for Movement Disorders}

Advance care planning (ACP) is "a process that supports adults at any age or stage of health in understanding and sharing their personal values, life goals, and preferences regarding future medical care" with the goal to ensure that people receive medical care that is consistent with their values and preferences during serious and chronic illness [39]. ACP conversations should occur across all stages of illness to address and anticipate shifting goals of care, changing clinical status, and prognosis. This includes advance directives (e.g. living will, medical orders for scope of treatment forms, medical durable power of attorney), discussions of future medical treatments including advanced therapies and end-of-life care (e.g. artificial nutrition, mechanical ventilation), and identification of an individual or persons for surrogate medical decision making.

\section{The Importance of Early ACP}

Dementia is a core feature of many movement disorders. In Parkinson's disease (PD) upwards of $80 \%$ of patients will develop dementia sometime during their disease course [40]. This poses a significant challenge to ACP. Early conversations take advantage of cognitively intact stages of disease, ensuring patients have a voice in their care and effectively communicate their wishes to families and medical providers. However, even in early stages, cognitive impairment is seen in up to a third of newly diagnosed PD patients and may affect aspects of decisional capacity [40-42]. When dementia prevents the patient from meaningful engagement in their care, clinicians frequently rely on caregivers and families to make medical decisions.

Recent research shows that the majority of patients desire early ACP conversations with their physician with $94 \%$ of PD patients wishing to discuss prognosis and treatment options around the time of diagnosis [43]. In one cross-sectional study surveying individuals with $\mathrm{PD}$, there was an overall preference for discussing end-of-life care and over half wished to have these conversations with their neurologist $\left[7^{\circ}\right]$. This study also found a higher proportion of PD patients complete advance directives when compared to cancer patients, further supporting the notion that patients have a strong desire for ACP communication.

\section{Special ACP Considerations in Movement Disorders}

ACP is also influenced by patient and stakeholder perspectives and misperceptions, disease severity, and the manner of care delivery [44]. Despite a demonstrable desire from patients and caregivers for a tool to facilitate discussions there is no consensus on any one specific approach to ACP for patients with movement disorders [45]. In a qualitative study, Jordan et al. reported persons with PD resonate with the metaphor of a "roadmap" to describe where they are in the course of illness, future expectations, and what potential decisions need to be made [45]. This model requires consultation with a movement disorder specialist given their intimate knowledge and clinical experience with these conditions. Effective approaches for ACP need to incorporate routine review of advance directives into standard of care. Discussions should involve the neurologist, patient, families, caregivers, and primary care provider and encourage interdisciplinary sharing of a patient's preferences and goals for their care.

Another potential tool for facilitating ACP into routine care is a pre-conversation ACP primer, personalized for patients and/or caregivers. This intervention has demonstrable benefits in serious, non-neurologic illness, with efficacy for improving the frequency and quality of goals of care communications [46], but has yet to be studied in movement disorders or other neurodegenerative diseases. 
Lastly, discussions surrounding advanced therapies, like deep brain stimulation (DBS), provide important opportunities for ACP in PD [47]. While DBS can significantly improve motor function and QOL [48], it is not without risk, including the potential for new neuropsychiatric disturbances and postoperative complications (e.g. intracranial hemorrhage, infection) [49]. One proposed approach is to inform patients of all probable outcomes, elicit existing care preferences with and without DBS, and use shared decision aids that are accurate and accessible to patients and surrogate decision makers [50].

\section{Palliative Care Needs Assessment}

In order to implement a PC approach for all patients with movement disorders, effective and systematic PC needs assessments are necessary. These will differ based on the care setting, but the overall goal is to identify and appropriately triage the multi-domain and under-recognized needs described. Many aspects of a PC approach can be implemented without formal needs assessment tools, and instead rely on updating clinical practice more broadly. As per recent American Academy of Neurology recommendations, those with PD should be screened for neuropsychiatric and cognitive symptoms at least annually; additionally, all providers should be discussing ACP at least once per year [51]. While not a formal needs assessment, simple and standardized screening for other common PC needs like feelings of isolation and care partner burnout could also expand PC delivery.

A number of methods have been explored to identify PC needs among those with movement disorders. These differ in their assessment strategies and goals $\left[52^{\circ}\right]$. The concept of PC triggers refers to the presence of certain clinical events to serve as an indicator for a PC intervention. Table 1 outlines triggers relevant to persons living with a movement disorder that should prompt consideration of a PC approach, including a serious illness discussion [53] or referral to a PC specialist [4]. Triggers may also be used to indicate a need for end-of-life care (Table 2) and Hussain et al., found that these triggers may be reduced to 4 factors using principal components analysis, including: 1) physical deterioration, dysphagia and complex symptoms; 2) weight loss and respiratory symptoms; 3 ) recurrent infections and cognitive decline; and 4) aspiration pneumonia [54].

A second approach is the use of checklists to systematically assess and manage PC issues, including non-motor symptoms, ACP, and caregiver wellbeing [55]. This method was employed in a recent randomized controlled trial of $\mathrm{PC}$ for those with PD with demonstrated efficacy [15].

More formal needs assessment tools also exist to explore PC needs within a context of triggering a referral for specialist PC. One example is the Needs Assessment Tool Parkinson's Disease (NAT-PD), which has been used in both clinical practice and research and bases its assessment of PC need on multiple domains of patient and caregiver function and distress [52"].

Finally, one can use various scales as a means of both assessing PC needs and tracking them over time. These scales generally focus on motor and non-motor symptom severity, though there are measures that explore spiritual, social, and financial needs as well $[56,57]$. There are also measures to assess care partner burden, including the Parkinson's disease caregiver burden questionnaire and Zarit Burden Interview $[58,59]$. Most tools have been adapted for PD and are derived from measures originally used in oncology and other fields; further adaptation and validation is likely be necessary for use in movement disorders beyond the parkinsonian syndromes. While many have been used as screening or outcome measures in clinical research, their utility in routine practice is unstudied.

\section{Models of Palliative Care Delivery}

There are several complementary models to implement a PC approach among patients with movement disorders. These differ based on the training, practice setting, and expertise of the PC providers, though all maintain a person-centered approach. The first is a consultative model, in which patients are referred to a palliative medicine specialist who provides care in addition to the patient's neurological care. The second is an integrated model, in which a palliative medicine specialist is integrated into a neurology practice. The third is the emerging subspecialty neuropalliative care, which represents a hybrid approach with experts trained in both palliative medicine and neurology. Finally, in the primary PC model, neurologists without fellowship or other specialist training in PC deliver a palliative approach in their own practice.

In the consultative and integrated models, a medical provider with subspecialty training in PC assists the treating neurologist in managing the palliative needs of the patient. Consultative PC is commonly used in Europe and the United Kingdom and there is evidence supporting its efficacy in neurodegenerative illnesses including PD [60]. In addition to the PC physician, the model often integrates a multidisciplinary PC team including nurses, social workers, chaplains, and counselors, among others $[61,62]$. The PC team provides care independently based on referral by the primary care physician or neurologist $[60,63]$. This is in contrast to the integrated model, which is more commonly used in North America. In this model, the PC specialist is integrated into a neurology clinic, seeing patients with specific PC needs. Miyasaki and colleagues pioneered the model, demonstrating benefit for improving symptoms among patients with advanced PD at a single site [ $\left.57^{\circ}\right]$. Broader implementation of this model in conjunction with a multidisciplinary care team was assessed in a recently completed multicenter randomized trial with similar results for improving QOL, reducing 
Table 1 Triggers for consideration of serious illness conversations \& palliative care approach

\begin{tabular}{|c|c|}
\hline $\begin{array}{l}\text { Movement } \\
\text { Disorder }\end{array}$ & Triggers \\
\hline General & $\begin{array}{l}\text { New diagnosis (or change in diagnosis) } \\
\text { Caregiver distress } \\
\text { Difficult emotions } \\
\text { Accelerating progression } \\
\text { Loss of independence or skills (e.g. driving) } \\
\text { Recent or recurrent hospitalizations } \\
\text { Dysphagia } \\
\text { Weight Loss } \\
\text { Spiritual or existential challenges (e.g. demoralization) }\end{array}$ \\
\hline PD [54] & $\begin{array}{l}\text { Severe motor symptoms (e.g. rigidity, postural instability) } \\
\text { Medication-refractory symptoms } \\
\text { Dysphagia affecting nutrition and medication adherence } \\
\text { Dementia } \\
\text { Behavioral disturbances (e.g. delusions, visual hallucinations) }\end{array}$ \\
\hline DLB $[87,88]$ & $\begin{array}{l}\text { Worsening dementia } \\
\text { Worsening visual hallucinations } \\
\text { Impaired mobility causing falls and trauma }\end{array}$ \\
\hline HD $[30,93,94]$ & $\begin{array}{l}\text { Worsening motor symptoms (e.g. chorea, dystonia) } \\
\text { Inability to maintain nutrition or hydration } \\
\text { Neuropsychiatric disturbances (e.g. depression, psychosis, disinhibition) }\end{array}$ \\
\hline PSP $[54,95]$ & $\begin{array}{l}\text { Visual impairment leading to reduced mobility \& falls } \\
\text { Neuropsychiatric disturbances (e.g. depression, apathy) } \\
\text { Severe motor symptoms (e.g. dystonia) }\end{array}$ \\
\hline MSA $[54,95]$ & $\begin{array}{l}\text { Dystonia } \\
\text { Autonomic dysregulation (e.g. orthostatic hypotension, urinary dysfunction, nausea, } \\
\text { constipation) } \\
\text { Breathing issues }\end{array}$ \\
\hline
\end{tabular}

Abbreviations: $\mathrm{EOL}=$ End-of-life; $\mathrm{PD}=$ Parkinson's disease; $\mathrm{DLB}=$ Dementia with Lewy Bodies; $\mathrm{HD}=$ Huntington disease; PSP = Progressive Supranuclear Palsy; MSA = Multiple Systems Atrophy symptom and care partner burden, and increasing advance directive completion among those with PD and related conditions [15].

While specialty PC can be beneficial for patients with movement disorders, many of these providers have limited training in managing neurological diseases [64] and may not have adequate training to manage $\mathrm{PC}$ needs specific to these patient populations, including management of medications or DBS near end-of-life [64-66]. This is especially true with an increasing focus on burden over the entire course of movement disorders, rather than in only the more advanced stages where PC needs may be more uniform. Neuropalliative specialists represent a subset of PC physicians with training in both neurology and PC [67]. These providers also work as part of a multidisciplinary team. However, their dual training facilitates a more tailored approach to managing patients with movement disorders. This allows them to anticipate PC needs, like screening for common non-motor symptoms in PD or being aware of the impact of apathy and agnosia in patients with HD [22]. A number of centers in the United States, Canada, and more broadly have neuropalliative programs [55], though there is limited formal assessment of the efficacy of the model or optimal methods for implementation.

Unfortunately, shortages in PC and neuropalliative specialists limit access to specialty PC [68, 69]. The primary PC model addresses these shortcomings by shifting PC delivery to the patient's treating neurologist or primary care physician [70]. This offers a pragmatic method to deliver neuropalliative care more broadly. While we refer to this model as primary palliative care, other terms used in the literature include holistic, comprehensive, or person-centered care. The common feature is the proactive focus on reducing disease burden for patients and care partners over the entire course of their illness. There is literature on the utilization of this model among those with HD [13], PD [71], and ataxia [72]. While the model holds substantial promise for broadening access to a PC approach, 
Table 2 Medicare hospice guidelines relevant to movement disorders and additional red flags to trigger end-of-life care and conversations

Condition Triggers

General [85]

Dementia [85]

Chronic neurodegenerative disease (movement disorders, neuromuscular diseases) [85]

\section{Movement Disorders:}

PD $[54,97]$ 1. Weight loss or low body mass index

2. Reduction in dopaminergic therapies secondary to loss of efficacy or increased side effects

3. Dysphagia limiting ability to take antiparkinsonian medication, with goal of care to avoid PEG tube placement

4. Severe behavioral disturbances (e.g. agitation, delirium)

5. Advanced dementia (see above)

DLB $[87,88]$ 1. Severe fluctuations in consciousness

2. Advanced dementia.(see above)

HD $[30,93,94] \quad 1$. Treatment-refractory, progressive motor symptoms (e.g. chorea, dystonia)

2. Severe neuropsychiatric disturbances (e.g. depression with suicidality)

3. Advanced dementia (see above)

PSP $[54,95]$ 1. Severe neuropsychiatric disturbances (e.g. depression, apathy)

2. Severe motor symptoms (e.g. dystonia)

MSA [54, 95] 1. Severe, treatment-refractory autonomic dysregulation

2. Arrhythmia

3. Stridor

Abbreviations: PPS = Palliative Performance Scale; FAST = Functional Assessment Staging; VC = vital capacity; ADLs = activities of daily living; $\mathrm{PD}=$ Parkinson's disease; $\mathrm{PEG}=$ percutaneous endoscopic gastrostomy; $\mathrm{DLB}=$ Dementia with Lewy Bodies; HD = Huntington disease; PSP = Progressive Supranuclear Palsy; MSA = Multiple Systems Atrophy 
insufficient education on PC principles, advanced communication, and managing total pain among neurology trainees may limit implementation [73]. This model is also not meant to cover all PC needs as complex and intensive management may be better handled by PC specialists. Ongoing work needs to focus on preparing neurologists to conduct regular ACP conversations, address care partner burden, and better integrate $\mathrm{PC}$ into their practice $[67,74]$.

\section{Emerging Delivery Methods: Home Care and Telemedicine}

Given the mobility challenges common to patients with advancing movement disorders, there is rising interest in identifying methods to bring PC directly to patients at home [69]. Fleisher and colleagues recently completed a pilot study assessing the feasibility and preliminary efficacy of home visits in homebound individuals with PD. They found the visits were feasible, and patient QOL was stable over 12 months, despite PD symptom progression [75']. The authors identified clear benefits for extending care to those with dementia and mobility challenges, including those who are bedbound. Ongoing work to assess broader implementation of this model is currently underway [76]. While there has been limited formal assessment of home visits for those with HD, the literature describes similar methods in clinical practice [13].

Telemedicine has also emerged as a model to broaden care delivery to populations in low provider availability areas or those with mobility challenges. This is particularly relevant for individuals with movement disorders, as the majority of patients with these conditions eventually become homebound $[77,78]$. Telemedicine has demonstrated utility for assessing or providing care to patients with a variety of movement disorders [79-82]. Similarly, there is rising use of telehealth to deliver PC to patients in their homes, though there has been limited formal assessment of these methods [83]. A 2019 review by Katz highlighted the current state of telehealth for PC delivery among those with PD, and identified telemedicine as a principal method to expand access to neurological care and PC $\left[84^{\circ}\right]$. Beyond direct care delivery, the author suggested these methods may also facilitate education of providers to deliver primary $\mathrm{PC}$.

The COVID-19 pandemic further underscores the potential role of telemedicine for providing PC to patients with movements disorders. In the pandemic's wake, healthcare systems have resorted to rapid shifts in care delivery to mitigate the spread of the virus, with an emphasis placed on telemedicine. In doing so, telemedicine has allowed many patients to continue to receive care and potentially improving healthcare delivery for patients with travel-limiting disease. As telemedicine services expand, PC clinicians should acknowledge the limitations of telemedicine and seek ways to make meaningful contact with patients virtually. Future models of telemedicine for PC should build on the knowledge gained during this unprecedented time.

\section{End-of-Life Care}

Many movement disorders are incurable and associated with increased mortality. Inevitably patients enter the end-of-life (EOL) or terminal phase of disease. Descriptions of EOL have historically focused on the time period 6-12 months before death, largely based on the United States Center for Medicare and Medicaid Services (CMS) Hospice criteria [85]. Table 2 summarizes general clinical events across chronic neurologic illness and dementia as well as specific issues among movement disorders which should consideration that patients are entering the EOL phase and may need EOL care or referral to hospice.

EOL needs are heterogenous with high variability between conditions and among individuals with the same disease. Patients may experience a protracted course or rapid decline. For parkinsonian syndromes like MSA and PSP, symptoms like respiratory failure, reduced mobility, profound autonomic instability, and difficulty swallowing are more predominant and may signal the terminal phase. With comparison to PD, EOL can be truncated in these conditions as autonomic dysfunction and/or respiratory failure can cause quick deterioration or sudden death. Dementia with Lewy Bodies (DLB), is characterized by early cognitive decline and neuropsychiatric disturbances (e.g. visual hallucinations, depression) preceding parkinsonism and is associated with shorter survival time (34 years from diagnosis to death) compared to PD and Alzheimer's disease [86]. In one study describing the EOL experience in DLB, mortality was linked to dementia-related complications, with $72 \%$ experiencing failure to thrive (due to inability to meet nutritional and hydration needs) and $23 \%$ succumbing to infection from pneumonia and aspiration [87 $]$. Caregivers and families are cognizant of these and report changes in appetite and increased visual hallucinations in advanced disease [88]. In a small proportion of individuals with DLB, antipsychotics were attributed to the cause of death [87 $]$, in line with descriptions of DLB-associated antipsychotic hypersensitivity [89]. This illustrates why movement disorder specialists should be included in EOL care, advising specific management decisions like avoidance of dopamineblocking medications (e.g. antipsychotics) and gradual weaning of antiparkinsonian when possible [66].

Dysphagia can also complicate EOL care in PD, DLB, and other movement disorders, leading to declining nutrition and fluid intake [90]. The use of percutaneous endoscopic gastrostomy (PEG) tubes in PD and related disorders typically occurs at later stages but has not been shown to improve QOL or survival [91]. Discussions surrounding PEG placement to mitigate the complications of dysphagia with an inability to 
take oral medications, are opportunities for a PC approach. This includes informed conversations regarding postoperative complications which might worsen QOL (e.g. infection, aspiration, bleeding) and should involve a specialist with experience in advanced movement disorders. As such, neurologists and movement disorder specialists are poised to improve patient QOL in advanced and terminal phases of disease.

Descriptions of the EOL phase of movement disorders can apprise ACP, patient and caregiver expectations, and inform evidence-based care. Through understanding characteristics which suggest EOL, referral to hospice services can be expedited. Early referral is recommended to ensure access to full hospice benefits and avoid missing out on resources for EOL care [1]. Of note, Medicare Guidelines are guidelines and not requirements. In making referrals, clear documentation of why you believe prognosis can be measured in months is more important than meeting all aspects of guidelines that could delay referrals [92].

\section{Research Priorities}

Research priorities for PC and Movement Disorders include:

\section{Disease Burden}

- Develop tools and strategies for more comprehensive identification of burdensome non-motor symptoms.

- Develop evidence-based interventions for managing common and challenging symptoms, psychosocial issues, and spiritual challenges for both patients and care partners (e.g. pain, grief, isolation, demoralization).

- Establish disease-specific trigger diagnosis/need guidelines to prompt consideration of a palliative care approach.

\section{Advance Care Planning}

- Develop strategies and tools for addressing diseasespecific ACP concerns (e.g. aspiration pneumonia) and barriers (e.g. apathy).

- Assess educational methods to enhance neurologist comfort with advance care planning and advanced communication practices.

- Dissemination and implementation studies of shareddecision-making aids in advance care planning for movement disorders for effective translation into clinical practice.

\section{Needs Assessment}

- Develop palliative needs assessment tools that are adaptable to different care settings and disease stage, including those with dementia

\section{Care Delivery}

- Develop best practices for sustainable dissemination of primary palliative care and neuropalliative care more broadly.

- Examine barriers to implementation of palliative care among neurologists.

- Evaluate methods to improve palliative care training among neurologists.

- Assess the utility of telehealth and home visits in PC dissemination.

- Understand and address disparities in knowledge, access and outcomes of PC interventions.

\section{End-of-Life Care}

- Establish disease-specific predictors of mortality to guide end-of-life care and referrals to hospice.

- Develop evidence-base for EOL interventions in movement disorders and improve care options (e.g. dopaminergic therapy options for persons with severe dysphagia at EOL).

\section{Conclusions}

Persons living with movement disorders and their families have significant PC needs that are poorly met under current models of care. Great strides have been made in documenting these needs and an emerging literature suggests that PC approaches are effective in improving many patient and caregiver-centered outcomes. There is still much work to be done which includes further understanding the unique PC needs of this population, adapting interventions from other fields (e.g. oncology) or developing novel intervention, and implementation and dissemination. This is an exciting and dynamic field where innovative research programs have a high potential for rapid translation into clinical practice.

\section{Compliance with Ethical Standards}

\section{Conflict of Interest All co-authors declare no conflicts of interest.}

Human and Animal Rights All reported studies/experiments with human or animal subjects performed by the authors have been previously published and complied with all applicable ethical standards (including the Helsinki declaration and its amendments, institutional/national research committee standards, and international/national/institutional guidelines). 


\section{References}

Papers of particular interest, published recently, have been highlighted as:

- Of importance

- Of major importance

1. Vaughan CL, Kluger BM. Palliative Care for Movement Disorders. Curr Treat Options Neurol. 2018;20(1):2. https://doi.org/10.1007/ s11940-018-0487-4.

2. Robinson MT, Holloway RG. Palliative Care in Neurology. Mayo Clin Proc. 2017;92(10):1592-601. https://doi.org/10.1016/j. mayocp.2017.08.003.

3. Quill TE, Abernethy AP. Generalist plus specialist palliative care - creating a more sustainable model. N Engl J Med. 2013;368(13):1173-5. https://doi.org/10.1056/ NEJMp1215620.

4. Creutzfeldt CJ, Kluger B. Holloway RG. Neuropalliative Care: Springer International Publishing; 2019.

5. Hudson PL, Toye C, Kristjanson LJ. Would people with Parkinson's disease benefit from palliative care? Palliat Med. 2006;20(2):87-94. https://doi.org/10.1191/ $0269216306 \mathrm{pm} 1108 \mathrm{oa}$.

6. Boersma I, Miyasaki J, Kutner J, Kluger B. Palliative care and neurology: time for a paradigm shift. Neurology. 2014;83(6):5617. https://doi.org/10.1212/wnl.0000000000000674.

7. Kluger BM, Shattuck J, Berk J, Sebring K, Jones W, Brunetti F et al. Defining Palliative Care Needs in Parkinson's Disease. Movement disorders clinical practice. 2019;6(2):125-31. https://doi.org/10. $1002 /$ mdc3.12702. Investigators conducted a cross-sectional survey to understand the palliative care needs of individuals with Parkinson disease and their effects on health related quality of life. The authors identified that high symptom burden, poor spiritual wellbeing, and grief were common and contributed to health related quality of life with disease burden comparable to advanced cancer.

8. The LN. Integrating palliative care into neurological practice. Lancet Neurol. 2017;16(7):489. https://doi.org/10.1016/s14744422(17)30176-x.

9. Stern J. Dying in the Neurosurgical I.C.U. The New York Times. 2020. https://www.nytimes.com/2020/01/14/well/live/brain-deadneurosurgical-ICU-communication.html. .

10. Palliative care in neurology. The American Academy of Neurology Ethics and Humanities Subcommittee. Neurology. 1996;46(3): $870-2$.

11.• Creutzfeldt CJ, Kluger B, Kelly AG, Lemmon M, Hwang DY, Galifianakis NB et al. Neuropalliative care: Priorities to move the field forward. Neurology. 2018;91(5):217-26. https://doi.org/10. $1212 /$ wnl.0000000000005916. A consortium of providers in neurology and palliative care defined clinical, educational, and research priorities to build on the evolving field of neuropalliative care. In doing so, they outline opportunities to improve quality of life using a palliative care approach for patients with neurologic illness.

12. Phillips LJ. Dropping the bomb: the experience of being diagnosed with Parkinson's disease. Geriatric nursing (New York, NY). 2006;27(6):362-9. https://doi.org/10.1016/j.gerinurse.2006.10. 012.

13. Tarolli CG, Chesire AM, Biglan KM. Palliative Care in Huntington Disease: Personal Reflections and a Review of the Literature. Tremor and other hyperkinetic movements (New York, NY). 2017;7:454. https://doi.org/10.7916/d88057c7. A summary of palliative care needs among individuals with Huntington disease, focusing on disease burden, care partner distress, advance care planning, and advanced disease and end-of-life needs among the population.

14. Tarolli CG, Holloway RG. Palliative care and Parkinson's disease: outpatient needs and models of care over the disease trajectory. Annals of palliative medicine. 2019. https://doi.org/10.21037/ apm.2019.11.11.

15.• Kluger BM, Miyasaki J, Katz M, Galifianakis N, Hall K, Pantilat S et al. Comparison of Integrated Outpatient Palliative Care With Standard Care in Patients With Parkinson Disease and Related Disorders: A Randomized Clinical Trial. JAMA neurology. 2020. https://doi.org/10.1001/jamaneurol.2019.4992. A randomized, controlled trial assessing the benefit of multidisciplinary integrated palliative care among those with Parkinson disease and related disorders. The authors found that the integrated model improved quality of life, symptom burden, caregiver distress, and advance directive completion.

16. Dayal AM, Jenkins ME, Jog MS, Kimpinski K, MacDonald P, Gofton TE. Palliative care discussions in multiple system atrophy: a retrospective review. Can J Neurol Sci. 2017;44(3):276-82. https://doi.org/10.1017/cjn.2016.439.

17. Goy ER, Carter J, Ganzini L. Neurologic disease at the end of life: caregiver descriptions of Parkinson disease and amyotrophic lateral sclerosis. J Palliat Med. 2008;11(4):548-54. https://doi.org/10. 1089/jpm.2007.0258.

18. Kirkwood SC, Su JL, Conneally P, Foroud T. Progression of symptoms in the early and middle stages of Huntington disease. Arch Neurol. 2001;58(2):273-8.

19. Shulman LM, Taback RL, Rabinstein AA, Weiner WJ. Nonrecognition of depression and other non-motor symptoms in Parkinson's disease. Parkinsonism Relat Disord. 2002;8(3):193-7.

20. Tarolli CG, Zimmerman GA, Auinger P, McIntosh S, Horowitz RK, Kluger BM, et al. Symptom burden among individuals with Parkinson disease: a national survey. Clinical Practice: Neurology; 2019.

21. Paulsen JS, Nehl C, Hoth KF, Kanz JE, Benjamin M, Conybeare R, et al. Depression and stages of Huntington's disease. J Neuropsychiatry Clin Neurosci. 2005;17(4):496-502. https://doi. org/10.1176/jnp.17.4.496.

22. McCusker E, Loy CT. The many facets of unawareness in huntington disease. Tremor and other hyperkinetic movements (New York, NY). 2014;4:257. https://doi.org/10.7916/d8fj2fd3.

23. Pagonabarraga J, Kulisevsky J, Strafella AP, Krack P. Apathy in Parkinson's disease: clinical features, neural substrates, diagnosis, and treatment. The Lancet Neurology. 2015;14(5):518-31. https:// doi.org/10.1016/s1474-4422(15)00019-8.

24. Ha AD, Jankovic J. Pain in Parkinson's disease. Movement disorders : official journal of the Movement Disorder Society. 2012;27(4):485-91. https://doi.org/10.1002/mds.23959.

25. Kilpatrick MM, Robinson MT. Addressing spiritual well-being as a means of improving quality of life in Parkinson disease. Annals of palliative medicine. 2019:apm.2019.11.30. https://doi.org/10. 21037/apm.2019.11.30.

26. Soleimani MA, Negarandeh R, Bastani F, Greysen R. Disrupted social connectedness in people with Parkinson's disease. $\mathrm{Br} \mathrm{J}$ Community Nurs. 2014;19(3):136-41. https://doi.org/10.12968/ bjen.2014.19.3.136.

27. Clark D. 'Total pain', disciplinary power and the body in the work of Cicely Saunders, 1958-1967. Social science \& medicine (1982). 1999;49(6):727-36. https://doi.org/10.1016/s0277-9536(99) $00098-2$.

28. Prigerson HG, Maciejewski PK. Grief and acceptance as opposite sides of the same coin: setting a research agenda to study peaceful acceptance of loss. Br J Psychiatry. 2008;193(6):435-7. https://doi. org/10.1192/bjp.bp.108.053157.

29. Sobel S, Cowan CB. Ambiguous loss and disenfranchised grief: the impact of DNA predictive testing on the family as a system. Fam 
Process. 2003;42(1):47-57. https://doi.org/10.1111/j.1545-5300. 2003.00047.x.

30. Dorsey ER, Beck CA, Darwin K, Nichols P, Brocht AF, Biglan $\mathrm{KM}$, et al. Natural history of Huntington disease. JAMA neurology. 2013;70(12):1520-30. https://doi.org/10.1001/jamaneurol.2013. 4408.

31. Perepezko K, Hinkle JT, Shepard MD, Fischer N, Broen MPG, Leentjens AFG, et al. Social role functioning in Parkinson's disease: a mixed-methods systematic review. International journal of geriatric psychiatry. 2019;34(8):1128-38. https://doi.org/10.1002/gps. 5137.

32. Puchalski C, Ferrell B, Virani R, Otis-Green S, Baird P, Bull J, et al. Improving the quality of spiritual care as a dimension of palliative care: the report of the consensus conference. J Palliat Med. 2009;12(10):885-904. https://doi.org/10.1089/jpm.2009.0142.

33. Prizer LP, Kluger BM, Sillau S, Katz M, Galifianakis N, Miyasaki JM. Correlates of spiritual wellbeing in persons living with Parkinson disease. Ann Palliat Med. 2020;9(Suppl 1):S16-S23. https://doi.org/10.21037/apm.2019.09.13.

34. Koo BB, Chow CA, Shah DR, Khan FH, Steinberg B, Derlein D, et al. Demoralization in Parkinson disease. Neurology. 2018;90(18):e1613-e7. https://doi.org/10.1212/WNL. 0000000000005425 .

35. Takai M, Takahashi M, Iwamitsu Y, Oishi S, Miyaoka H. Subjective experiences of family caregivers of patients with dementia as predictive factors of quality of life. Psychogeriatrics. 2011;11(2):98-104. https://doi.org/10.1111/j.1479-8301.2011. 00354.x

36. Pickett TAE, Paulsen JS. Caregiver burden and Huntington's disease. Rehabilitation Psychology. 2007;52:311-8.

37. Berger S, Chen T, Eldridge J, Thomas CA, Habermann B, TickleDegnen $\mathrm{L}$. The self-management balancing act of spousal care partners in the case of Parkinson's disease. Disabil Rehabil. 2019;41(8): 887-95. https://doi.org/10.1080/09638288.2017.1413427.

38. Adelman RD, Tmanova LL, Delgado D, Dion S, Lachs MS. Caregiver burden: a clinical review. Jama. 2014;311(10):105260. https://doi.org/10.1001/jama.2014.304.

39. Sudore RL, Lum HD, You JJ, Hanson LC, Meier DE, Pantilat SZ, et al. Defining advance care planning for adults: a consensus definition from a multidisciplinary Delphi panel. J Pain Symptom Manag. 2017;53(5):821-32 e1. https://doi.org/10.1016/j. jpainsymman.2016.12.331.

40. Meireles J, Massano J. Cognitive impairment and dementia in Parkinson's disease: clinical features, diagnosis, and management. Front Neurol. 2012;3:88. https://doi.org/10.3389/fneur.2012. 00088 .

41. Foltynie T, Brayne CE, Robbins TW, Barker RA. The cognitive ability of an incident cohort of Parkinson's patients in the UK. The CamPaIGN study Brain. 2004;127(Pt 3):550-60. https://doi.org/10. 1093/brain/awh067.

42. Abu Snineh M, Camicioli R, Miyasaki JM. Decisional capacity for advanced care directives in Parkinson's disease with cognitive concerns. Parkinsonism Relat Disord. 2017;39:77-9. https://doi.org/ 10.1016/j.parkreldis.2017.03.006.

43. Tuck KK, Brod L, Nutt J, Fromme EK. Preferences of patients with Parkinson's disease for communication about advanced care planning. Am J Hosp Palliat Care. 2015;32(1):68-77. https://doi.org/10. 1177/1049909113504241.

44. Lum HD, Jordan SR, Brungardt A, Ayele R, Katz M, Miyasaki JM, et al. Framing advance care planning in Parkinson disease: patient and care partner perspectives. Neurology. 2019;92(22):e2571-e9. https://doi.org/10.1212/wnl.0000000000007552.

45. Jordan SR, Kluger B, Ayele R, Brungardt A, Hall A, Jones J et al. Optimizing future planning in Parkinson disease: suggestions for a comprehensive roadmap from patients and care partners. Ann
Palliat Med. 2020;9(Suppl 1):S63-s74. https://doi.org/10.21037/ apm.2019.09.10.

46. Curtis JR, Downey L, Back AL, Nielsen EL, Paul S, Lahdya AZ, et al. Effect of a patient and clinician communication-priming intervention on patient-reported goals-of-care discussions between patients with serious illness and clinicians: a randomized clinical trial. JAMA Intern Med. 2018;178(7):930-40. https://doi.org/10. 1001/jamainternmed.2018.2317.

47. Aslakson RA, Schuster AL, Reardon J, Lynch T, Suarez-Cuervo C, Miller JA, et al. Promoting perioperative advance care planning: a systematic review of advance care planning decision aids. J Comp Eff Res. 2015;4(6):615-50. https://doi.org/10.2217/cer.15.43.

48. Weaver FM, Follett K, Stern M, Hur K, Harris C, Marks WJ, et al. Bilateral deep brain stimulation vs best medical therapy for patients with advanced Parkinson disease: a randomized controlled trial. JAMA. 2009;301(1):63-73. https://doi.org/10.1001/jama.2008. 929.

49. Ludvic Z, Thomas F, Patricia L, Marwan IH. Reducing hemorrhagic complications in functional neurosurgery: a large case series and systematic literature review. Journal of Neurosurgery JNS. 2012;116(1):84-94. https://doi.org/10.3171/2011.8.JNS101407.

50. Sokol LL, Young MJ, Paparian J, Kluger BM, Lum HD, Besbris J, et al. Advance care planning in Parkinson's disease: ethical challenges and future directions. NPJ Parkinsons Dis. 2019;5:24. https://doi.org/10.1038/s41531-019-0098-0.

51. Factor SA, Bennett A, Hohler AD, Wang D, Miyasaki JM. Quality improvement in neurology: Parkinson disease update quality measurement set. Executive summary. 2016;86(24):2278-83. https:// doi.org/10.1212/wnl.0000000000002670.

52. Richfield EW, Johnson MJ. Palliative care in Parkinson's disease: review of needs assessment tools. Annals of palliative medicine. 2019:apm.2019.09.18. https://doi.org/10.21037/apm.2019.09.18. This review article provides an overview of the growing number of needs assessment tools to assess palliative care needs among those with Parkinson disease and their caregivers, describing the psychometric properties, validated settings, and benefits and drawbacks of each measure.

53. Bernacki RE, Block SD. American College of Physicians High Value Care Task F. communication about serious illness care goals: a review and synthesis of best practices. JAMA Intern Med. 2014;174(12):1994-2003. https://doi.org/10.1001/jamainternmed. 2014.5271.

54. Hussain J, Allgar V, Oliver D. Palliative care triggers in progressive neurodegenerative conditions: an evaluation using a multi-Centre retrospective case record review and principal component analysis. Palliat Med. 2018;32(4):716-25. https://doi.org/10.1177/ 0269216318755884.

55. Kluger BM, Persenaire MJ, Holden SK, Palmer LT, Redwine H, Berk J et al. Implementation issues relevant to outpatient neurology palliative care. Annals of palliative medicine. 2018;7(3):339-48. https://doi.org/10.21037/apm.2017.10.06.

56. Saleem TZ, Higginson IJ, Chaudhuri KR, Martin A, Burman R, Leigh PN. Symptom prevalence, severity and palliative care needs assessment using the palliative outcome scale: a cross-sectional study of patients with Parkinson's disease and related neurological conditions. Palliat Med. 2013;27(8):722-31. https://doi.org/10. $1177 / 0269216312465783$.

57.• Miyasaki JM, Long J, Mancini D, Moro E, Fox SH, Lang AE et al. Palliative care for advanced Parkinson disease: an interdisciplinary clinic and new scale, the ESAS-PD. Parkinsonism \& related disorders. 2012;18 Suppl 3:S6-9. https://doi.org/10.1016/j.parkreldis. 2012.06.013. This single-site study evaluated the utility of a multidisciplinary integrated palliative care clinic for individuals with Parkinson disease, assessing a novel symptom assessment scale, the Edmonton Symptom Assessment ScaleParkinson disease. The authors demonstrated this scale was 
easy to administer and that integrated palliative care could reduce symptom burden in $\mathrm{PD}$.

58. Martinez-Martin P, Arroyo S, Rojo-Abuin JM, RodriguezBlazquez C, Frades B, de Pedro Cuesta J. Burden, perceived health status, and mood among caregivers of Parkinson's disease patients. Movement disorders : official journal of the Movement Disorder Society. 2008;23(12):1673-80. https://doi.org/10.1002/mds. 22106

59. Zhong M, Evans A, Peppard R, Velakoulis D. Validity and reliability of the PDCB: a tool for the assessment of caregiver burden in Parkinson's disease. Int Psychogeriatr. 2013;25(9):1437-41. https:// doi.org/10.1017/S1041610213000586.

60. Veronese S, Gallo G, Valle A, Cugno C, Chio A, Calvo A, et al. Specialist palliative care improves the quality of life in advanced neurodegenerative disorders: NE-PAL, a pilot randomised controlled study. BMJ Support Palliat Care. 2017;7(2):164-72. https://doi.org/10.1136/bmjspcare-2014-000788.

61. Crawford GB, Price SD. Team working: palliative care as a model of interdisciplinary practice. Med J Aust. 2003;179(6 Suppl):S324.

62. Kluger BM, Katz M, Galifianakis N, Pantilat SZ, Kutner JS, Sillau $\mathrm{S}$, et al. Does outpatient palliative care improve patient-centered outcomes in Parkinson's disease: rationale, design, and implementation of a pragmatic comparative effectiveness trial. Contemporary clinical trials. 2019;79:28-36. https://doi.org/10.1016/j.cct.2019. 02.005 .

63. Oliver D, Veronese S. Specialist palliative care for Parkinson's disease. Annals of palliative medicine. 2020:apm.2019.12.01. https:// doi.org/10.21037/apm.2019.12.01.

64. Manu E, Marks A, Berkman CS, Mullan P, Montagnini M, Vitale CA. Self-perceived competence among medical residents in skills needed to care for patients with advanced dementia versus metastatic cancer. J Cancer Educ. 2012;27(3):515-20. https://doi.org/10. 1007/s13187-012-0351-2.

65. Turner-Stokes L, Sykes N, Silber E, Khatri A, Sutton L, Young E. From diagnosis to death: exploring the interface between neurology, rehabilitation and palliative care in managing people with longterm neurological conditions. Clin Med (Lond). 2007;7(2):129-36.

66. Katz M, Goto Y, Kluger BM, Galifianakis NB, Miyasaki JM, Kutner JS, et al. Top ten tips palliative care clinicians should know about Parkinson's disease and related disorders. J Palliat Med. 2018;21(10):1507-17. https://doi.org/10.1089/jpm.2018.0390.

67. Robinson MT, Barrett KM. Emerging subspecialties in neurology: neuropalliative care. Neurology. 2014;82(21):e180-2. https://doi. org/10.1212/wnl.0000000000000453.

68. Lupu D, Quigley L, Mehfoud N, Salsberg ES. The growing demand for hospice and palliative medicine physicians: will the supply keep up? J Pain Symptom Manag. 2018;55(4):1216-23. https://doi.org/ 10.1016/j.jpainsymman.2018.01.011.

69. Ramanathan U, Tanuseputro P. Improving access to palliative care for persons with Parkinson disease. Annals of palliative medicine. 2020:apm.2019.11.10. https://doi.org/10.21037/apm.2019.11.10.

70. Creutzfeldt CJ, Robinson MT, Holloway RG. Neurologists as primary palliative care providers: communication and practice approaches. Neurology Clinical practice. 2016;6(1):40-8. https://doi. org/10.1212/cpj.0000000000000213.

71. Radder DLM, de Vries NM, Riksen NP, Diamond SJ, Gross D, Gold DR, et al. Multidisciplinary care for people with Parkinson's disease: the new kids on the block! Expert Rev Neurother. 2019;19(2):145-57. https://doi.org/10.1080/14737175.2019. 1561285.

72. Stephen CD, Brizzi KT, Bouffard MA, Gomery P, Sullivan SL, Mello J, et al. The Comprehensive Management of Cerebellar Ataxia in adults. Curr Treat Options Neurol. 2019;21(3):9. https:// doi.org/10.1007/s11940-019-0549-2.
73. Mehta AK, Najjar S, May N, Shah B, Blackhall L. A needs assessment of palliative care education among the United States adult neurology residency programs. J Palliat Med. 2018;21(10):144857. https://doi.org/10.1089/jpm.2018.0191.

74.• Kluger BM, Fox S, Timmons S, Katz M, Galifianakis NB, Subramanian I et al. Palliative care and Parkinson's disease: Meeting summary and recommendations for clinical research. Parkinsonism \& related disorders. 2017;37:19-26. https://doi.org/ 10.1016/j.parkreldis.2017.01.008. A review conducted by experts in palliative care, neurology, and movement disorders to provide recommendations for research and practice with recommedations for translational research applying palliative care approaches with efficacy in non-neurologic disease into practical use for PD including: needs assessment tools, oucome measures, and research priorties for implementation, dissemination, and education.

75. Fleisher JE, Sweeney MM, Oyler S, Meisel T, Friede N, Di Rocco A et al. Disease severity and quality of life in homebound people with advanced Parkinson disease. A pilot study. 2019:https://doi. org/10.1212/CPJ.0000000000000716. https://doi.org/10.1212/cpj. 0000000000000716 . The authors conducted a pilot study of a interdisciplinary home visits for homebound patients with advanced Parkinson disease, demonstrating efficacy at maintaining quality of life over 1 year, despite advancing motor symptoms.

76. Fleisher JE, Klostermann EC, Hess SP, Lee J, Myrick E, Chodosh J. Interdisciplinary palliative care for people with advanced Parkinson's disease: a view from the home. Annals of palliative medicine. 2019. https://doi.org/10.21037/apm.2019.09.12.

77. Dall TM, Storm MV, Chakrabarti R, Drogan O, Keran CM, Donofrio PD, et al. Supply and demand analysis of the current and future US neurology workforce. Neurology. 2013;81(5):470 8. https://doi.org/10.1212/WNL.0b013e318294b1cf.

78. Dorsey ER, George BP, Leff B, Willis AW. The coming crisis: obtaining care for the growing burden of neurodegenerative conditions. Neurology. 2013;80(21):1989-96. https://doi.org/10.1212/ WNL.0b013e318293e2ce.

79. Beck CA, Beran DB, Biglan KM, Boyd CM, Dorsey ER, Schmidt $\mathrm{PN}$, et al. National randomized controlled trial of virtual house calls for Parkinson disease. Neurology. 2017;89(11):1152-61. https:// doi.org/10.1212/wnl.0000000000004357.

80. Tarolli CG, Zimmerman GA, Goldenthal S, Feldman B, Berk S, Siddiqi $\mathrm{B}$ et al. Video research visits for atypical parkinsonian syndromes among Fox Trial Finder participants. Neurology: Clinical Practice. 2019:https://doi.org/10.1212/CPJ.0000000000000680. https://doi.org/10.1212/cpj.0000000000000680.

81. Bull MT, Darwin K, Venkataraman V, Wagner J, Beck CA, Dorsey ER, et al. A pilot study of virtual visits in Huntington disease. Journal of Huntington's disease. 2014;3(2):189-95. https://doi.org/ 10.3233 /jhd-140102.

82. Schneider RB, Biglan KM. The promise of telemedicine for chronic neurological disorders: the example of Parkinson's disease. The Lancet Neurology. 2017;16(7):541-51. https://doi.org/10.1016/ s1474-4422(17)30167-9.

83. Hancock S, Preston N, Jones H, Gadoud A. Telehealth in palliative care is being described but not evaluated: a systematic review. BMC palliative care. 2019;18(1):114. https://doi.org/10.1186/ s12904-019-0495-5.

84. Katz M. Telehealth increases access to palliative care for people with Parkinson's disease and related disorders. Annals of palliative medicine. 2019. https://doi.org/10.21037/apm.2019.11.12. The author describes the role of telehealth to expand the delivery of palliative care to individuals with Parkinson disease and related disorders through direct provision of palliative care services, and through remote education in palliative care for treating neurologists. 
85. Organization NH. Medical guidelines for determining prognosis in selected non-cancer diseases. Hosp J. 1996;11(2):47-63.

86. Moylett S, Price A, Cardinal RN, Aarsland D, Mueller C, Stewart $\mathrm{R}$, et al. Clinical presentation, diagnostic features, and mortality in dementia with Lewy bodies. J Alzheimers Dis. 2019;67(3):9951005. https://doi.org/10.3233/JAD-180877.

87. Armstrong MJ, Alliance S, Corsentino P, DeKosky ST, Taylor A. Cause of Death and End-of-Life Experiences in Individuals with Dementia with Lewy Bodies. J Am Geriatr Soc. 2019;67(1):6773. https://doi.org/10.1111/jgs.15608. This study examines the perspectives of caregives and families of recently deceased patients with dementia with Lewy Bodies (DLB) and adds to descriptions of end-of-life, including issues which arise in DLB patients receiving hospice care $(80 \%$ of respondents).

88. Armstrong MJ, Alliance S, Taylor A, Corsentino P, Galvin JE. Endof-life experiences in dementia with Lewy bodies: qualitative interviews with former caregivers. PLoS One. 2019;14(5):e0217039. https://doi.org/10.1371/journal.pone.0217039.

89. McKeith I, Fairbairn A, Perry R, Thompson P, Perry E. Neuroleptic sensitivity in patients with senile dementia of Lewy body type. BMJ. 1992;305(6855):673-8. https://doi.org/10.1136/bmj.305. 6855.673.

90. Lum HD, Kluger BM. Palliative Care for Parkinson Disease. Clin Geriatr Med. 2020;36(1):149-57. https://doi.org/10.1016/j.cger. 2019.09.013.

91. Sarkar P, Cole A, Scolding NJ, Rice CM. Percutaneous endoscopic gastrostomy tube insertion in neurodegenerative disease: a retrospective study and literature review. Clin Endosc. 2017;50(3): 270-8. https://doi.org/10.5946/ce.2016.106.

92. Mitchell SL, Miller SC, Teno JM, Kiely DK, Davis RB, Shaffer ML. Prediction of 6-month survival of nursing home residents with advanced dementia using ADEPT vs hospice eligibility guidelines. Jama. 2010;304(17):1929-35. https://doi.org/10.1001/jama.2010. 1572.

93. Downing NR, Goodnight $\mathrm{S}$, Chae S, Perlmutter JS, McCormack M, Hahn E, et al. Factors associated with end-of-life planning in Huntington disease. Am J Hosp Palliat Care. 2018;35(3):440-7. https://doi.org/10.1177/1049909117708195.

94. Kavanaugh MS, Noh H, Zhang L. Caregiving youth knowledge and perceptions of parental end-of-life wishes in Huntington's disease. J Soc Work End Life Palliat Care. 2016;12(4):348-65. https:// doi.org/10.1080/15524256.2016.1252828.

95. Wiblin L, Lee M, Burn D. Palliative care and its emerging role in multiple system atrophy and progressive Supranuclear palsy. Parkinsonism Relat Disord. 2017;34:7-14. https://doi.org/10. 1016/j.parkreldis.2016.10.013.

96. Reisberg B. Functional assessment staging (FAST). Psychopharmacol Bull. 1988;24(4):653-9.

97. Goy ER, Bohlig A, Carter J, Ganzini L. Identifying predictors of hospice eligibility in patients with Parkinson disease. The American journal of hospice \& palliative care. 2015;32(1):29-33. https://doi. org/10.1177/1049909113502119.

98. Glover TL, Kluger BM. Chapter 30 - Palliative medicine and endof-life care. In: Dekosky ST, Asthana S, editors. Handbook of Clinical Neurology. Elsevier; 2019. p. 545-561.

Publisher's NotePublisher's Note Springer Nature remains neutral with regard to jurisdictional claims in published maps and institutional affiliations. 